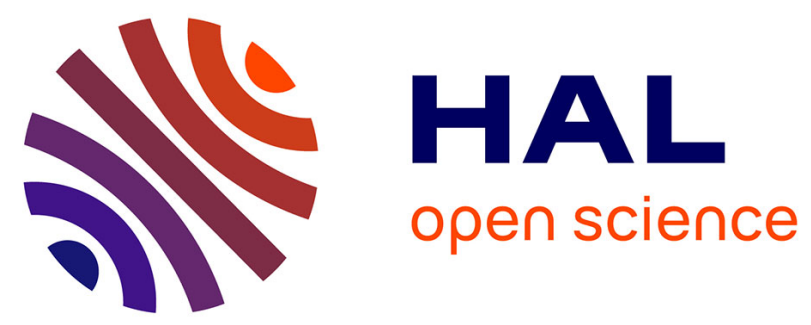

\title{
RF oscillators stabilized by temperature compensated HBARs based on LiNbO3/Quartz combination
}

T. Baron, G. Martin, E. Lebrasseur, B. François, S. Ballandras, D. Gachon, P.-P. Lasagne, A. Reinhardt, L. Chomeloux, J.-M. Lesage

\section{To cite this version:}

T. Baron, G. Martin, E. Lebrasseur, B. François, S. Ballandras, et al.. RF oscillators stabilized by temperature compensated HBARs based on LiNbO3/Quartz combination. 5th Joint Conference of the 65th IEEE International Frequency Control Symposium/25th European Frequency and Time Forum, May 2011, San Francisco, United States. pp.879-882, 10.1109/FCS.2011.5977814 • hal-00651277

\section{HAL Id: hal-00651277 \\ https://hal.science/hal-00651277}

Submitted on 14 Apr 2021

HAL is a multi-disciplinary open access archive for the deposit and dissemination of scientific research documents, whether they are published or not. The documents may come from teaching and research institutions in France or abroad, or from public or private research centers.
L'archive ouverte pluridisciplinaire HAL, est destinée au dépôt et à la diffusion de documents scientifiques de niveau recherche, publiés ou non, émanant des établissements d'enseignement et de recherche français ou étrangers, des laboratoires publics ou privés.

\section{(c)(1)}

Distributed under a Creative Commons Attribution| 4.0 International License 


\section{RF oscillators stabilized by temperature compensated HBARs based on $\mathrm{LiNbO}_{3} / \mathrm{Quartz}$ combination}

\author{
T. Baron, G. Martin, E. Lebrasseur, B. François, S. \\ Ballandras \\ FEMTO-ST, UMR 6174 CNRS-UFC-ENSMM-UTBM \\ Time and Frequency Department \\ Besançon, France \\ sylvain.ballandras@femto-st.fr
}

\author{
D. Gachon \\ Laboratoire PROMES-CNRS, UPR 8521 \\ Université de Perpignan Via Domitia, \\ Perpignan, France
}

\begin{abstract}
In this work, we develop a radio-frequency oscillator operating near the $434 \mathrm{MHz}$-centered ISM band to validate the temperature compensated capability of HBAR based on combining $\mathrm{LiNbO}_{3}$ and Quartz single crystal plates for such purposes. Electrical and thermoelectric characterizations have shown QF product in excess of $10^{13}$ and a third order frequencytemperature behavior. A phase noise better than $-160 \mathrm{dBc} / \mathrm{Hz}$ at $100 \mathrm{kHz}$ has been measured as well as a $-165 \mathrm{dBc} / \mathrm{Hz}$ level at $1 \mathrm{MHz}$ from the carrier. First results showing that the resonator stability is better than $10^{-9}$ under room conditions. Further work is expected to lower that level well below $\mathbf{1 0}^{-10}$.
\end{abstract}

\section{INTRODUCTION}

Radio-Frequency (RF) oscillators can be stabilized by various resonating devices. Their stability is mainly conditioned by the spectral quality of the resonator even if the oscillator loop electronics must be optimized to lower the generated noise as much as possible. For mid-term stability, temperature compensation as a key point and allows for notably improving the corresponding figure of merit. In a previous work [1], we have shown the possibility to build temperature compensated High overtone Bulk Acoustic Resonators (HBARs) combining $\mathrm{LiNbO}_{3}$ and Quartz single crystal plates for the excitation of high order modes exhibiting cubic frequency-temperature behavior. In this work, we develop a radio-frequency oscillator operating near the 434 MHz-centered ISM band to validate the capability of the above-mentioned HBAR for such purposes. The composite substrate have been built using a 3-inch $(\mathrm{YXl}) / 163^{\circ} \mathrm{LiNbO}_{3}$ cut wafer bounded and thinned down to $15 \mu \mathrm{m}$ onto a $350 \mu \mathrm{m}$ thick (YXlt) $/ 34^{\circ} / 90^{\circ}$ quartz base.

Single-port resonators operating near $434 \mathrm{MHz}$ (exploiting the third harmonic of the thinned niobate plate as the HBAR transducer) have been then manufactured. Electrical and thermoelectric characterizations have shown quality factor of the resonance in excess of 25000 , yielding a QF product in

\author{
P.-P. Lasagne, A. Reinhardt \\ CEA-LETI, LCRF, \\ Grenoble, France \\ Luc Chomeloux \\ SENSeOR SAS \\ Mougins, France
Jean-Marc Lesage
DGA, CELAR
Rennes, France

excess of $10^{13}$ and a third order frequency-temperature behavior. A SAW filter was used to select the ISM band and to filter the high spectral density HBAR response. The oscillator then has been measured using a phase noise automatic bench (R\&S FSUP26 spectrum and phase noise analyzer). A phase noise better than $-160 \mathrm{dBc} / \mathrm{Hz}$ at $100 \mathrm{kHz}$ has been measured as well as a $-165 \mathrm{dBc} / \mathrm{Hz}$ level at $1 \mathrm{MHz}$ from the carrier. Mid term stability also have been achieved, first results showing resonator stability better than $10^{-9}$ under room conditions. Further work are expected to lower that level well below $10^{-10}$.

The first section of the paper discusses the design of the resonator based on thermoelastic computation of the temperature coefficients of frequency (TCF) of each mode of the structure. The basic theory is first recalled and general relations are provided to select the material stack thicknesses for a given mode order/frequency operating condition. A very brief description of the device fabrication is provided and experimental characterization of the resonators is reported. The oscillator architecture is depicted and the stability measurements detailed. As a conclusion, comparison with SAW-based oscillator is achieved and possible improvements of the oscillator is discussed

\section{DeVICE ANALYSIS AND DESIGN}

\section{A. HBAR Temperature Coefficient of Frequency (TCF)}

The celebrated Campbell\&Jones method [2] is used here for predicting the TCF of any mode of a given HBAR. As it has been reported hundred times in previous papers, only the main basic equation is reported below:

$$
f=\frac{V}{2 e} \rightarrow \frac{d f}{f}(T)=\frac{d V}{V}(T)-\frac{d e}{e}(T)
$$


which means that the frequency changes due to temperature variations are computed as the difference between the development of the velocity and of the stack thickness vs temperature. As discussed in [1], Lithium Niobate and Quartz have been associated for the fabrication of shear-waver based HBARs. $\mathrm{LiNbO}_{3}$ provides crystal orientations for which very strongly coupled shear waves exist $\left(\mathrm{k}_{\mathrm{t}}^{2}\right.$ in excess of $\left.45 \%\right)$ whereas AT cut of Quartz allows for compensating second order frequency-temperature effects [3]. Although this idea was already proposed using other material combinations [4], no real design process was presented until now and therefore the possibility to actually determine structures allowing for high frequency operation with first order TCF smaller than $1 \mathrm{ppm} . \mathrm{K}^{-1}$ was quite hypothetic. Second order compensation was even not imagined in [4]. Figure 1 shows the evolution of the $\mathrm{TCF}_{1}$ of almost all the modes of thinned $(\mathrm{YX} l) / 163^{\circ}$ $\mathrm{LiNbO}_{3}$ layer atop a $(\mathrm{YX} l t) / 36^{\circ} / 90^{\circ}$ Quartz plate for various Niobate/Quartz thickness ratios, always assuming a Niobate layer much thinner than the Quartz substrate (which allows for neglecting the differential thermoelastic stress within the stack). One can see that depending on the harmonic number, the $\mathrm{TCF}_{1}$ changes from +1 to $-14 \mathrm{ppm} \cdot \mathrm{K}^{-1}$. Furthermore, depending on the harmonic of the transducer alone, the $\mathrm{TCF}_{1}$ may notably change and thus it cannot be considered as a simple periodic function vs harmonic number. Therefore, it is mandatory to accurately consider all the actual feature of the structure for an accurate design of a resonator, i.e. the operation frequency, the harmonic number and the thickness ratio for a given structure. To complete this, one should also account for the actual thickness of the device as this parameter will control the possibility to select one (frequency/harmonic number) couple. Finally, it clearly appears that the analysis of such HBAR TCF requires a numerical analysis and that if an intuitive approach allows for a first order definition of crystal orientations, the complicated distribution of energy within the stack vs all the structure parameters induces more intrication in the design process.

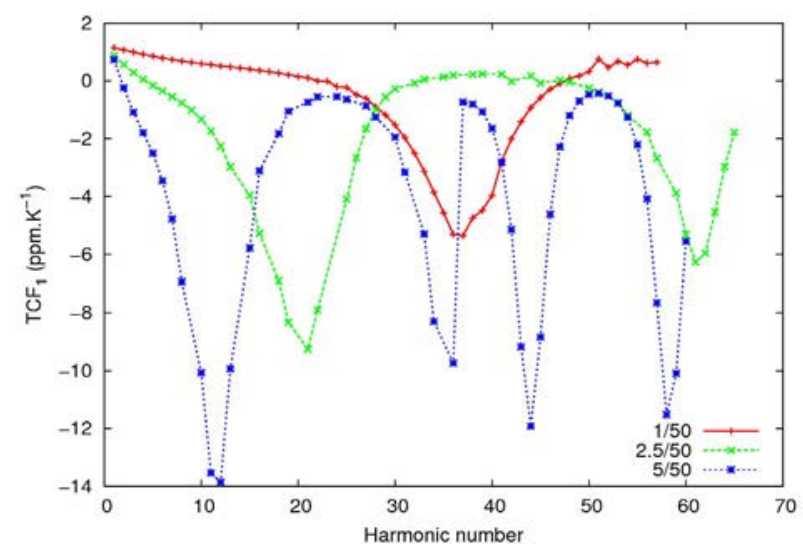

Figure 1.

Plot of the TCF of a HBAR built on a $(\mathrm{YX} l) / 163^{\circ}$ $\mathrm{LiNbO}_{3}$ thinned plate bonded on $(\mathrm{YX} l t) / 36 / 90$ Quartz substrate for various Niobate/Quartz thickness ratio (Quartz thickness arbitrary fixed to 50 $\mathrm{\mu m}$ )
As an illustration of these considerations, the evolution of the TCF of the most strongly coupled mode of the structure (coinciding with the fundamental mode of the niobate plate alone) has been plotted vs niobate thickness (Fig.2). A TCF vs Niobate/Quartz ratio law has been derived from this curve, yielding the following expression:

$$
T C F_{1}=42.5 \times R_{t}+3.2 \times \log \left(200 R_{t}\right)
$$

where $R_{t}$ is the Niobate/Quartz ratio, thicknesses and $\mathrm{TCF}_{1}$ being expressed in $\mu \mathrm{m}$ and in ppm. $\mathrm{K}^{-1}$ implicitly.

Considering now the $\mathrm{TCF}_{1}$ evolution vs quartz cut angle $\theta$ (rotation around $\mathrm{X}$ axis), one can set the following complementary law:

$$
T C F_{1}=(\theta-35 .) \times 5.10^{-6}
$$

Using these relations allows one to show that the most coupled mode of the structure is temperature compensated for $R_{t}=1 / 50$ for the $(\mathrm{YX} l t) / 34^{\circ} / 90^{\circ}$ quartz cut, whereas the $(\mathrm{YX} l t) /$ $33^{\circ} / 90^{\circ}$ and $(\mathrm{YX} l t) / 32^{\circ} / 90^{\circ}$ cuts will be selected for $\mathrm{R}_{\mathrm{t}}$ respectively equal to $2.5 / 50$ and $5 / 50$.

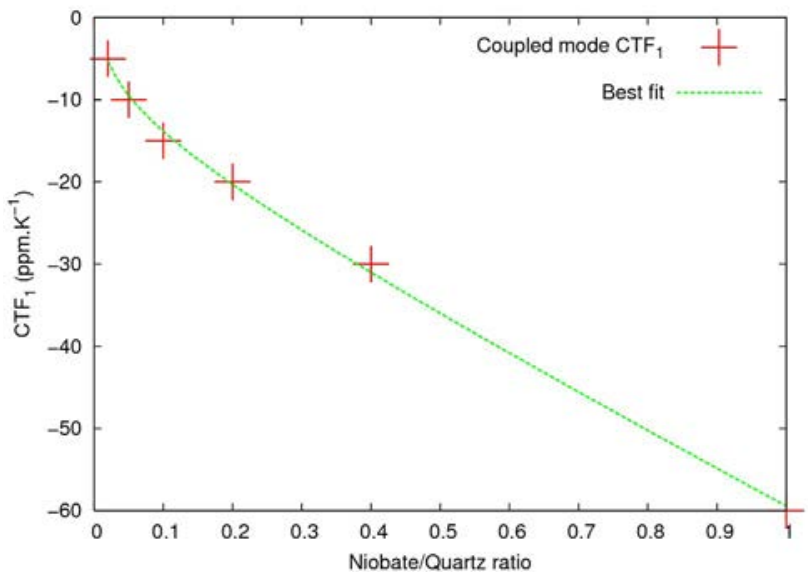

Figure 2. Plot of the TCF of a HBAR built on a (Yxl)/163 $\mathrm{LiNbO}_{3}$ thinned plate bonded on (Yxlt)/36/90 Quartz substrate for various Niobate/Quartz thickness ratio (Quartz thickness arbitrary fixed to $50 \mu \mathrm{m}$ )

\section{B. $434 \mathrm{MHz}$ resonator design}

The design of the $434 \mathrm{MHz}$ centered resonator has been done considering our capability to thin down $\mathrm{LiNbO}_{3}$ wafers. A typical thickness of $15 \mu \mathrm{m} \pm 2 \mu \mathrm{m}$ then must be considered, the Quartz thickness being deduced along the theoretical analysis presented above. Assuming a phase velocity of the shear mode in the $\mathrm{LiNbO}_{3}$ layer near $4000 \mathrm{~m} \cdot \mathrm{s}^{-1}$, the third harmonic of the fundamental mode then is easily excited at the expected frequency. To achieve the temperature compensation of the mode, the quartz cut angle and plate thickness then has to be fixed. A $R_{t}$ value of $2.5 / 50$ is considered as a trade-off between the spectral density of modes and the ease to manufacture the material stack. 
Consequently, the quartz thickness is found near $270 \mu \mathrm{m}$ for a cut angle corresponding to (YXlt) $/ 34^{\circ} / 90^{\circ}$. Once again for manufacture simplicity, standard quartz wafer thicknesses are considered, yielding a value of $350 \mu \mathrm{m}$. The $\mathrm{LiNbO}_{3}$ thickness then is adjusted to $14 \mu \mathrm{m}$ according to the above considerations $\left(R_{t}\right.$ actual value $\left.2 / 50\right)$. Validation of such a configuration has been achieved theoretically by computing the admittance of the corresponding device and then its theoretical TCF. An equivalent quality coefficient $Q$ of 20,000 has been considered for Quartz whereas a $Q$ of 100,000 was affected to $\mathrm{LiNbO}_{3}$. Au electrodes are used at the interface $(t=300 \mathrm{~nm}, Q \sim 1000)$ and $\mathrm{Al}$ ones at the top surface $(t=250 \mathrm{~nm}, Q \sim 2000)$. An effective $\mathrm{Q}$ value slightly larger than 20,000 then is predicted for a $k_{s}^{2}$ of 1,9\%o (Fig.3). Temperature compensation is checked by plotting both $\mathrm{TCF}_{1}$ and second order $\mathrm{TCF}_{2}$ for each resonance near $434 \mathrm{MHz}$, as shown in Fig.4. For such a configuration, one can see that $\mathrm{TCF}_{1}$ smaller than $1 \mathrm{ppm} . \mathrm{K}^{-1}$ can be obtained together with $\mathrm{TCF}_{2}$ of less than $5 \mathrm{ppb} . \mathrm{K}^{-2}$.

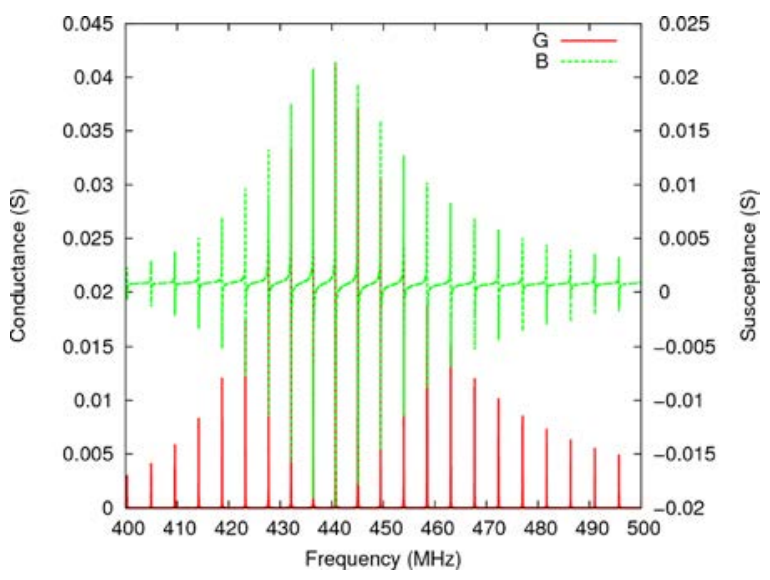

Figure 3. Theoretical admittance of a HBAR built on a $14 \mu \mathrm{m}$ thick (YXl)/163 ${ }^{\circ} \mathrm{LiNbO}_{3}$ plate onto $350 \mu \mathrm{m}$ thick (YXIt) $/ 34^{\circ} / 90^{\circ}$ Quartz

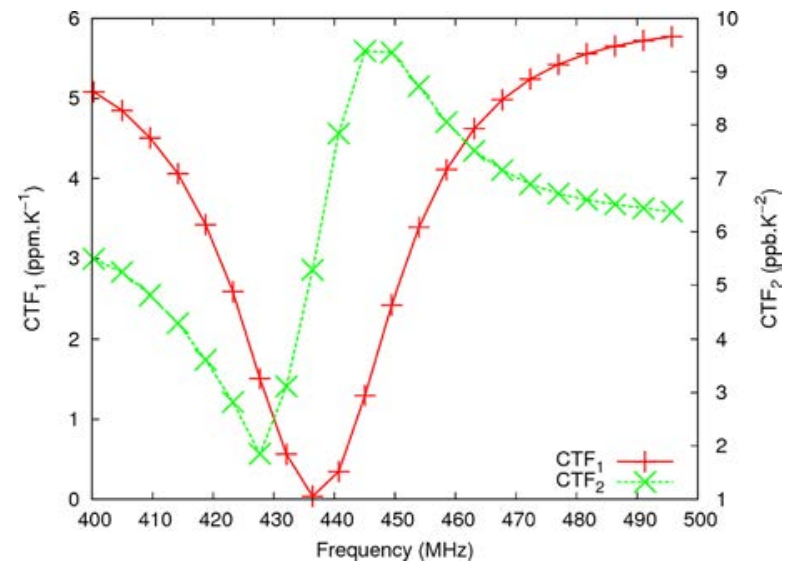

Figure 4. $\quad 1^{\text {st }}$ and $2^{\text {nd }}$ order TCF of the above $\mathrm{LiNbO}_{3} /$ Quartz HBAR, temperature compensation achieved between 430 and $440 \mathrm{MHz}$.

\section{EXPERIMENTAL IMPLEMENTATION}

\section{A. HBAR fabrication}

As mentioned above, only some information is reported here as most of the process has been already presented in details [1]. $\mathrm{LiNbO}_{3}$ and Quartz are bonded together using thin $\mathrm{Cr} / \mathrm{Au}$ films deposited on both wafer sides to be bounded and therefore used both as diffusion layers and interface electrode. A pre-bonding is first achieved using either an EVG bounder or a Suss Microtech CL200 megasonic cleaner. The bounding then is reinforced by applying a quite strong homogeneous pressure during a few tenth minutes, yielding then an almost perfect acoustic adhesion between both material. Top electrodes are then deposited using standard lithography processes.

\section{B. Resonator characterization}

Conforming to the above design and manufacturing process, several devices have been fabricated and tested to select the most appropriate one for frequency stabilization in the ISM band. Figure 5 shows one example of resonator admittance from which electromechanical coupling $k_{s}^{2}$ and Q factor are deduced, respectively at about $0.2 \%$ and 25,946 , yielding a $\mathrm{Q}$ factor of $1.13 \times 10^{13}$, much better than Rayleigh wave based resonators on Quartz considering the same frequency. One can note that $\mathrm{Q}$ factor in excess of 30000 also were measured (QF products in excess of $\left.1.3 \times 10^{13}\right)$, but for frequencies slightly out of the ISM band. The TCFs have been again tested to demonstrate the predicted compensation effect.

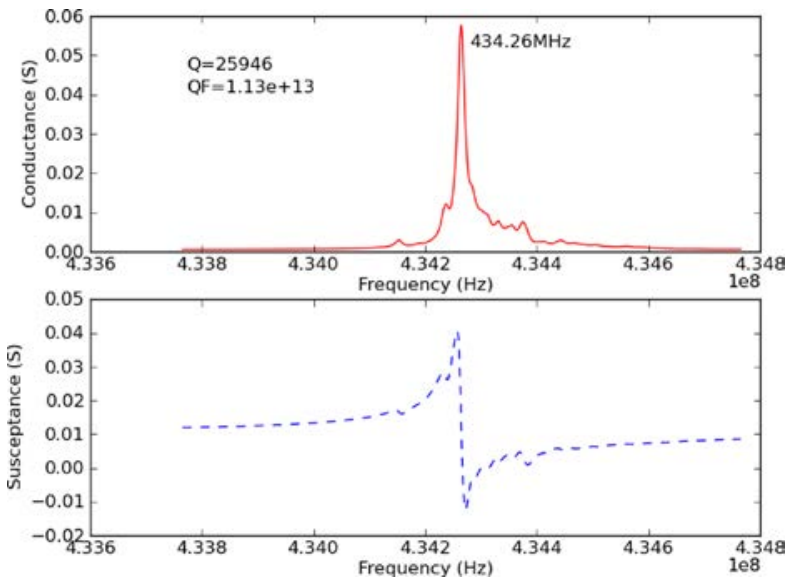

Figure 5. Experimental measurements (admittance) of a HBAR based on $(\mathrm{YXI}) / 163^{\circ} \mathrm{LiNbO}_{3}$ plate onto $350 \mu \mathrm{m}$ thick (YXlt) $/ 34^{\circ} / 90^{\circ}$ Quartz

\section{Oscillator stabilization}

The implemented oscillator once again is very similar to what has been already presented for SAW devices [5] and therefore will not be detailed here. It is a Colpitts-type negative resistance circuit to which a buffer stage has been 
added to isolate the oscillating loop and provide sufficient signal for the oscillator characterization. Figure 6 shows the characterization of the oscillator output using a spectrum analyzer, showing the definition of the resonance and also proving the possibility to actually select the ISM band by filtering.

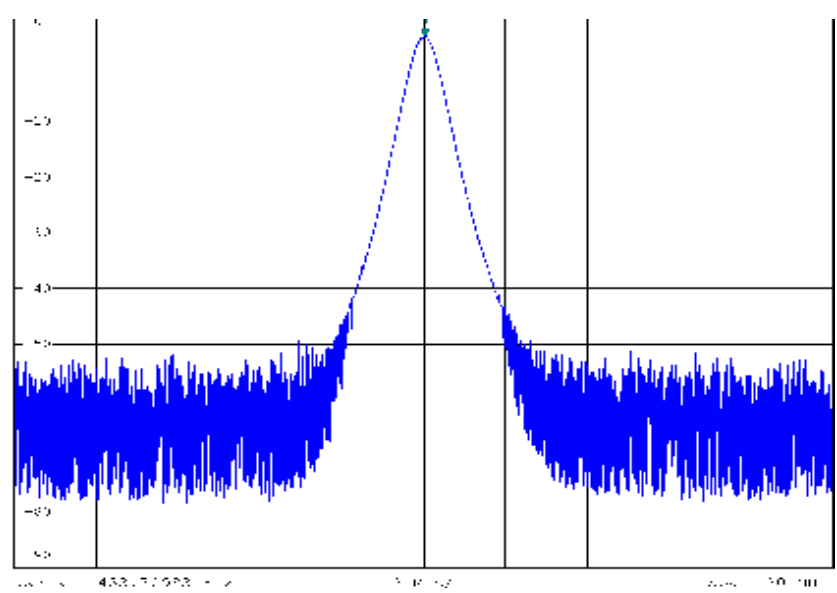

Figure 6.

Spectrum of the oscillator output signal, close to the ISM center $(433.7 \mathrm{MHz})$

Figure 7 shows the phase noise of the oscillator. The noise floor is at $-165 \mathrm{dBc} / \mathrm{Hz}$ and the phase noise at $10 \mathrm{kHZ}$ is $-140 \mathrm{dBc} / \mathrm{Hz}$.

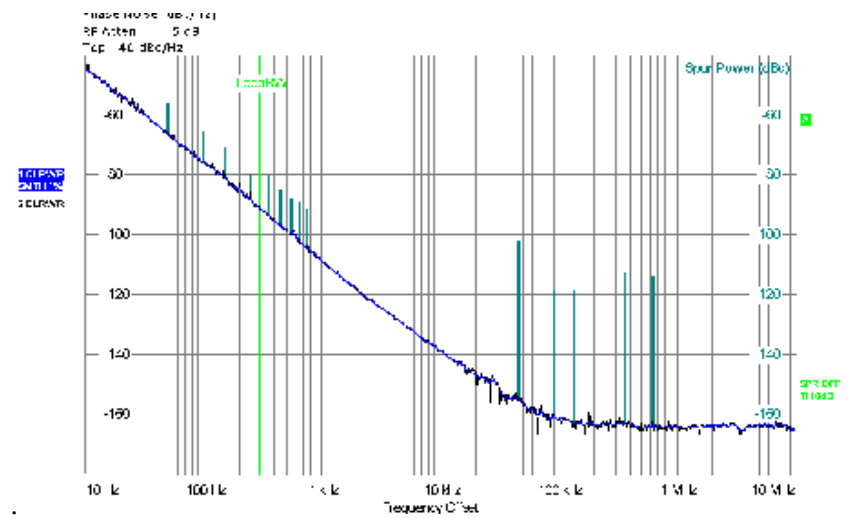

Figure 7. Phase noise of the Colpitts oscillator.

Figure 8 show Allan variance of the oscillator output signal. The oscillator based on HBAR temperature compensated presents a relative stability of near $2 \times 10^{-10}$ over 2 seconds of integration at room conditions.

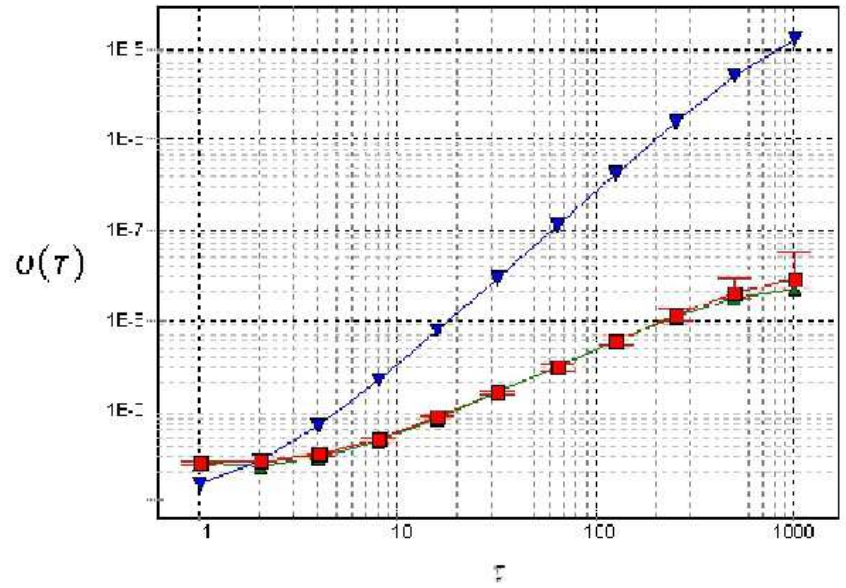

Figure 8. Allan Variance of the oscillator output signal, yielding a relative stability near $2 \times 10^{-10}$ over 2 seconds of integration at room conditions

\section{Conclusion}

In this work, we develop a radio-frequency oscillator operating near the $434 \mathrm{MHz}$-centered ISM band to validate the temperature compensated capability of HBAR based on combining LiNbO3 and Quartz single crystal plates for such purposes. Electrical and thermoelectric characterizations have shown QF product in excess of 1013 and a third order frequency-temperature behavior. A phase noise better than $-160 \mathrm{dBc} / \mathrm{Hz}$ at $100 \mathrm{kHz}$ has been measured as well as a $-165 \mathrm{dBc} / \mathrm{Hz}$ level at $1 \mathrm{MHz}$ from the carrier. First results showing that the resonator stability is better than 10-9 under room conditions over 2 seconds. Further work is expected to lower that level well below 10-10. To achieve this objective, excitation of resonator will be increase, test will be done under controlled temperature condition, and electromechanical coupling coefficient will be increase. Towards ultimate stability allows us competition with SAW based oscillators.

\section{REFERENCES}

[1] T. Baron et al, Temperature compensated radio-frequency harmonic bulk acoustic resonators, Proc.of the IEEE IFCS, pp. 652 - 655, 2010

[2] J.J. Campbell, W.R. Jones, "A method for estimating crystals cuts and propagation direction for excitation of piezoelectric surface waves", IEEE Trans. On Sonics and Ultrasonics, Vol. 15, pp. 209-217, 1968

[3] S. Ballandras, D. Gachon, RESONATEUR HBAR A STABILITE EN TEMPERATURE ELEVEE, French patent \#FR2932333 (B1), PCT extension WO2009156658 (A1)

[4] Curran Daniel R \& Al, US Patent \#3401275A, 1968-09-10

[5] B. François, Fabrication and Characterization of a SAW-Oscillatorbased Sensing System Including an Integrated Reciprocal Counter and a Wireless ZigBee Transmission System, Proc. of the IEEE International Ultrasonics Symposium, 2010

This work is supported by the FCE - DGCIS under grant \#092906659/60/61. 